\title{
Predatory bug Picromerus bidens communicates at different frequency levels
}

Research Article

Andrej Čokl*, Alenka Žunič, Meta Virant-Doberlet

Department of Entomology,

National Institute of Biology,

SI-1000 Ljubljana, Slovenia

Received 06 September 2010; Accepted 19 January 2011

\begin{abstract}
The Asopinae (Heteroptera: Pentatomidae) are a subfamily of stinkbugs with predaceous feeding habits and poorly understood communication systems. In this study we recorded vibratory signals emitted by Picromerus bidens L. on a non-resonant substrate and investigated their frequency characteristics. Males and females produced signals by vibration of the abdomen and tremulation. The female and male songs produced by abdominal vibrations showed gender-specific time structure. There were no differences in the temporal patterns of male or female tremulatory signals. The signals produced by abdominal vibrations were emitted below $600 \mathrm{~Hz}$ whereas tremulatory signals had frequency ranges extending up to $4 \mathrm{kHz}$. Spectra of male vibratory signals produced by abdominal vibrations contained different peaks, each of which may be dominant within the same song sequence. Males alternated with each other during production of rivalry signals, using different dominant frequency levels. We show that the vibratory song repertoire of $P$. bidens is broader than those of other predatory stinkbugs that have been investigated. The emission of vibrational signals with different dominant frequencies but the same production mechanism has not yet been described in heteropteran insects, and may facilitate location of individual sources of vibration within a group.
\end{abstract}

Keywords: Substrate-borne vibrational communication • Picromerus bidens • Signal production • Signal frequency variation

(C) Versita Sp. z 0.0 .

\section{Introduction}

The subfamily Asopinae, with about 300 species, differs from other pentatomid subfamilies by having mainly predaceous feeding habits [1] which demand welldeveloped sensory and communication abilities. One species, the spined soldier bug Podisus maculiventris (Say), has received considerable attention with regard to its distribution, life history, biology, and food preferences. Its rearing, predator-prey relationships, and potential as a biological control agent were summarized by De Clercq [1]. The first attractant pheromone for any true bugs was identified for $P$. maculiventris [2]. This species also exploits the substrate as a medium for detection of vibrational cues produced by chewing prey [3], and for transmission of signals involved in intraspecific communication [4,5].

Less attention has been paid to the Palaearctic asopine species Picromerus bidens $\mathrm{L}$. which is found predominantly in damp, shrubby areas and forests on vegetation up to 2 mabove the ground [1].Asageneralised predatoritfeeds on the larvae of many insect species [6-9]. $P$. bidens disperses mainly by walking or probably by flight to avoid overpopulation of specific sites in summer $[6,10,11]$. Abdominal or sternal glands have not been found in P. bidens [12] and to our knowledge nothing is known about chemical communication between conspecifics. Thus, $P$. bidens represents an interesting model for behavioural studies because chemical communication has been shown to accompany substrate-borne sound communication in many of the stinkbug species investigated to date [13].

Gogala [14] observed stereotyped movements in male $P$. bidens which accompanied the emission of vibratory signals during mating behaviour. Recently Shestakov [15] described the vibratory signals of four asopine stinkbug species from European Russia. In P. bidens the author [15] identified only a male rival song and hypothesized that different signal spectra are the result 
of different distances between the sensor and the source. Gogala [14] showed that the song repertoire of $P$. bidens includes additional songs besides the male rivalry song [15]. Furthermore, the different frequency spectra of vibratory signals of various species [14] indicate that different mechanisms are probably involved in vibratory signal production. We also predict that the apparent lack of chemical signalling [12] may be compensated for by a larger variety of other types of signals.

In the present study we describe the song repertoire of $P$. bidens by recording vibratory signals on a nonresonant substrate for comparison with published data on $P$. maculiventris and other previously investigated pentatomid species. We hypothesize that the apparent lack of an attractant pheromone in $P$. bidens has resulted in an enlarged repertoire of vibratory signals transmitted through the substrate. Here, we also test the hypothesis that the spectra, and particularly the frequency characteristics, of rival signals for $P$. bidens change due to the physical parameters of the substrate and the position of the singing insect relative to the vibration sensor [15]. Such changes may represent a strategy to reduce interference by competitive signallers, as was shown recently with the phytophagous stink bug Nezara viridula L. (Pentatomidae: Pentatominae) [16].

\section{Experimental Procedures}

\subsection{Material}

For all the experiments we used 4-10 d old adult $P$. bidens males and females, reared in a laboratory culture at the All-Russian Centre for Plant Quarantine in Bykovo, Moscow Region, Russia. Bugs were separated by gender within the first day after the final moult.

\subsection{Signal recording and analysis}

All experiments were conducted at the All-Russian Centre for Plant Quarantine in Bykovo. Signals were recorded in December 2009 between 0900 and $1600 \mathrm{~h}$ under laboratory and daylight conditions at room temperature $\left(23 \pm 1^{\circ} \mathrm{C}\right)$ and $40-50 \%$ relative humidity. For comparative reasons, and to eliminate the influence of substrate on characteristics of vibratory signals, we used the same recording technique as described for the spined soldier bug $P$. maculiventris [4]. Signals were recorded from bugs placed on a $10-\mathrm{cm}$-diameter low-midrange loudspeaker $(40-6000 \mathrm{~Hz}$ frequency response, 8- $\Omega$ impedance, Radio Shack, Taipei, Taiwan). Loudspeaker membrane vibrations induced by singing bugs were amplified by a microphone amplifier (Sonifex, Redbox amplifier, tape RB-MA, Sonifex Ltd., Irthlingborough, Northamptonshire, United
Kingdom), then digitized and stored via a sound card (24-bit, 96-kHz, 100-dB signal-to-noise ratio; Sound Blaster Extigy, Creative Laboratories Inc., Milpitas, Ca) on a laptop computer using Cool Edit Pro version 2.0 software (Adobe Systems Inc., San Jose, Ca). We analyzed recorded signals with Sound Forge version 6.0 software (Sonic Foundry Inc., Madison, WI). Frequency characteristics were described by frequency spectra (FFT size 32768, FFT overlap 75\%, smoothing window Blackman-Harris, display range $60 \mathrm{~dB}$, normalized to the dominant frequency peak amplitude value as $0 \mathrm{~dB}$ ) and sonograms (FFT size 8192, FFT overlap 99\%, smoothing window Blackman-Harris, display range $20 \mathrm{~dB}$ ). Frequency values of spectral peaks were determined by the program with $1 \mathrm{~Hz}$ precision.

\subsection{Data presentation}

Songs were characterized as sequences of signals in the form of pulses and/or pulse trains. Pulses are defined as unitary homogenous parcels of vibrations of finite duration [17] and pulse trains as pulses arranged into repeatable and temporally distinct groups. We determined gender origin of emitted signals by observing the animals being tested. Song types were differentiated by temporal (duration and repetition time) and spectral properties of signals as well as by their behavioural context. In each spectrum we measured the frequency value of the dominant spectral peak (DFP further in the text), and of the peak with the second highest amplitude (SdFP1 further in the text) below the DFP. Data are represented as means of values obtained for different bugs when the difference between individual means was not significantly different (ANOVA, P>0.05). In the case of significant individual differences the minimal and maximal individual mean values are shown.

\section{Results}

When pairs of $P$. bidens adults were placed on the loudspeaker membrane, male and female substrateborne signals were produced by abdomen vibrations (vibratory signals) and tremulations (tremulatory signals) visible to the observer. According to differences in their temporal and spectral characteristics (Table 1) we describe them as one female (FS) and four different male (MS1-4) song types. Male and female tremulatory signals showed no gender specificity.

\subsection{Female song (FS)}

The FS was emitted as a continuous sequence of regularly repeated pulse trains (Figure $1 \mathrm{~A}$, left) whose duration varied according to the pulse number per 


\begin{tabular}{|c|c|c|c|c|}
\hline Song & Pulse train duration & Pulse train repetition time & Pulse duration & Pulse repetition time \\
\hline FS & $\begin{array}{c}334 \pm 65(n=8) \\
1076 \pm 130(n=3)\end{array}$ & $2350 \pm 994(n=62, N=6)$ & $\begin{array}{c}75 \pm 16(n=52) \\
104 \pm 24(n=42)\end{array}$ & $\begin{array}{r}91 \pm 28(n=57) \\
120 \pm 24(n=52)\end{array}$ \\
\hline MS1 & - & - & $\begin{array}{c}63 \pm 14(n=10) \\
209 \pm 63(n=19)\end{array}$ & $\begin{array}{l}93 \pm 20(n=15) \\
549 \pm 232(n=9)\end{array}$ \\
\hline MS2 & - & - & $\begin{array}{l}180 \pm 22(n=12) \\
708 \pm 105(n=20)\end{array}$ & $\begin{array}{c}235 \pm 30(n=12) 7 \\
20 \pm 231(n=49)\end{array}$ \\
\hline MS3 & $\begin{array}{c}4248 \text { (24 pulse/train) } \\
12784 \text { (52 pulse/train) }\end{array}$ & Irregular & $\begin{array}{l}142 \pm 31(n=24) \\
234 \pm 34(n=41)\end{array}$ & $\begin{array}{l}175 \pm 41(n=23) \\
283 \pm 43(n=40)\end{array}$ \\
\hline MS4 & - & - & $\begin{aligned} \text { (A) } 91 & \pm 21(n=9) \\
177 & \pm 32(n=23) \\
\text { (B) } 119 & \pm 22(n=9) \\
258 & \pm 43(n=32)\end{aligned}$ & $\begin{array}{c}\text { (A) } 206 \pm 52(n=62) \\
\text { (B) } 318 \pm 81(n=9) \\
511 \pm 77(n=5)\end{array}$ \\
\hline TR & - & - & $\begin{array}{c}81 \pm 23(n=20) \\
123 \pm 50(n=20)\end{array}$ & irregular \\
\hline
\end{tabular}

Table 1. Minimal and maximal individual mean $( \pm S D)$ values of female and male vibratory (FS, MS1-4) and tremulatory (TR) pulse or pulse train duration and repetition time in ms. Minimal mean pulse train duration is shown for FS pulse trains $(n=8)$ with 3 pulses per pulse train and mean maximal duration for FS pulse trains $(n=3)$ with 9 pulses per pulse train. FS pulse train repetition time is averaged for 6 different females whose individual means did not differ significantly (ANOVA, $\mathrm{P}=0.8736$, NS). Single minimal and maximal duration values are shown for MS3 pulse trains. Repetition time for MS4 is given separately for the male A and B. FS, female song; MS1-4, male song 1-4; TR, tremulatory signals

group. A representative spectrogram of a $10 \mathrm{~s}$ long pulse train sequence shows the prominent dominant frequency peak at $126 \mathrm{~Hz}$ (Figure 1B, left). Mean individual dominant frequency values varied significantly (ANOVA, $P<0.01$ ) among 6 tested females between 118 $\pm 16 \mathrm{~Hz}(\mathrm{n}=53)$ and $127 \pm 7 \mathrm{~Hz}(\mathrm{n}=57)$. Single FS pulse dominant frequency values $(n=354, N=6)$ were mainly distributed between 90 and $155 \mathrm{~Hz}$ with less than $1 \%$ of them above $160 \mathrm{~Hz}$, and the SdFP1 values $(n=354$, $\mathrm{N}=6$ ) ranged between 50 and $250 \mathrm{~Hz}$ with peaks around 90 (4.5\%), 165 (9.3\%), 195 (5.6\%) and $225 \mathrm{~Hz}(3.1 \%)$ (Figure 1C, left). Females emitted the FS spontaneously prior to any male singing. FS triggered the emission of male vibratory responses (MS1-MS3) and their steady pulse train repetition rate was interrupted only during emission of male rivalry signals (MS4).

\subsection{Male songs (MS1-4)}

The MS1 (Figure 1A, right) is described as a sequence of short pulses with mean durations from 63 to $210 \mathrm{~ms}$ and mean repetition times between 93 and $550 \mathrm{~ms}$. The frequency spectrogram of a $10 \mathrm{~s}$ long MS1 sequence shows the dominant frequency peak at $126 \mathrm{~Hz}$ and the SdFP1 at $235 \mathrm{~Hz}$ (Figure 1B, right). Frequency characteristics of single pulses showed high variability: the dominant frequency $(n=1007, N=14)$ ranged between 75 and $250 \mathrm{~Hz}$ with most centred on peaks at $100(4.1 \%), 125(7.7 \%)$ and $150(9.8 \%) \mathrm{Hz}$. The corresponding single pulse SdFP1 values $(n=367$, $\mathrm{N}=14$ ) varied between 50 and $350 \mathrm{~Hz}$ with peaks at
90 (3.3\%), 135 (5.4\%), 165 (6.0\%) and $225(4.6 \%) \mathrm{Hz}$ (Figure 1C, right). SdFP1 values increased with increasing DFP at levels between $50-150 \mathrm{~Hz}$ and $100-300 \mathrm{~Hz}$. The MS1 was emitted as the first vibratory response to FS and developed to MS2 and MS3 during prolonged communication with a female.

MS2 pulses (Figure 2A, left) differed from MS1 by their mean duration varying individually above $180 \mathrm{~ms}$ (Table 1). The frequency spectrum of a $10 \mathrm{~s}$ MS2 pulse sequence showed two distinct peaks with almost equal amplitude (DFP at $104 \mathrm{~Hz}$ and SdFP at $207 \mathrm{~Hz}$ ) (Figure 2B, left). MS2 pulses were also characterized by frequency modulation (FM) between 160 and $200 \mathrm{~Hz}$ (Figure 4C). The DFP of single MS2 pulses ( $n=201$, $\mathrm{N}=10)$ varied either around $105(29.9 \%)$ or $185 \mathrm{~Hz}$ (6.5\%). Compared with MS1 the MS2 SdFP1 relative distribution $(n=175, N=10)$ was more regular (Figure 2C, left). SdFP1 values of pulses with the DFP around $100 \mathrm{~Hz}$ were distributed above $150 \mathrm{~Hz}$ with the peak at $210 \mathrm{~Hz}(9.7 \%)$ and those of the pulses with DFP above $150 \mathrm{~Hz}$ ranged around $85 \mathrm{~Hz}(10.3 \%, \mathrm{n}=175, \mathrm{~N}=10)$. The $210 \mathrm{~Hz}$ SdFP peak corresponded to the position of the first harmonic of the DFP at $105 \mathrm{~Hz}$. The MS2 has its origin in MS1, appears closely connected with FS, and provides the basis for the MS4 signals.

MS3 (Figure 2A, right) differed from the other male song types by pulses grouped into irregularly repeated pulse trains whose duration depended on the number of included pulses: the shortest pulse train $(4248 \mathrm{~ms})$ recorded in our experiments contained 24 pulses and the 


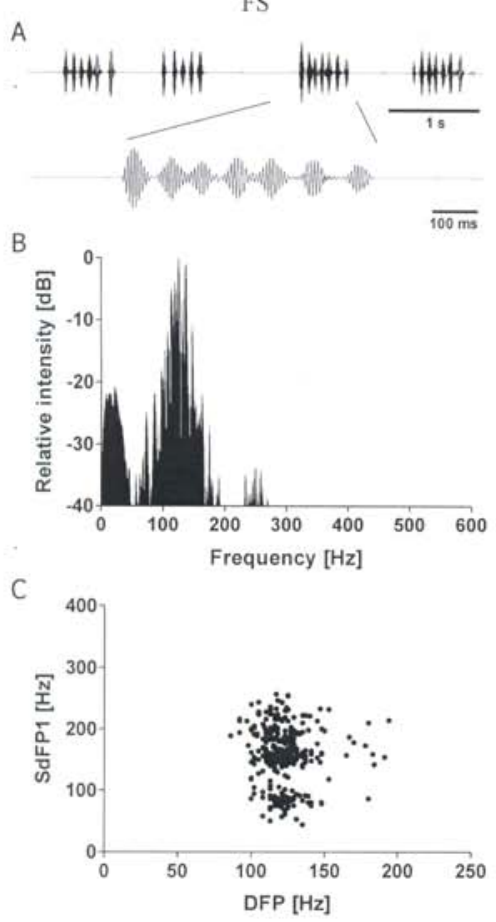

MS1
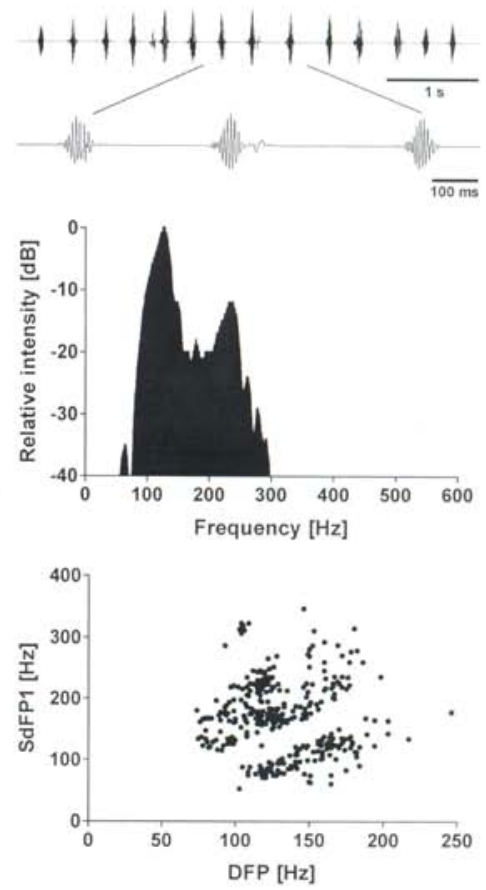

Figure 1. Oscillograms (A), frequency spectra (B) (10 s sequences) and distribution (C) of frequency values of the female song (FS, left) and the first male song (MS1, right) signal dominant spectral peak (DFP) and corresponding peak with the second highest amplitude (SdFP1).

MS2

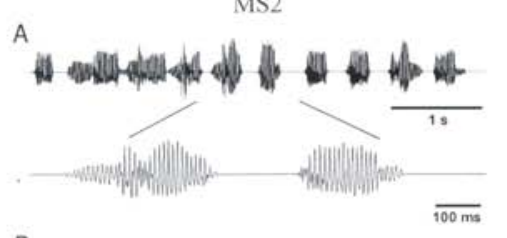

B

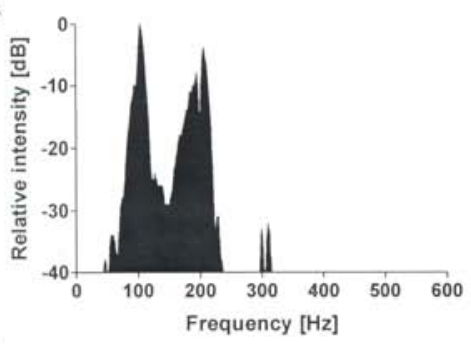

C

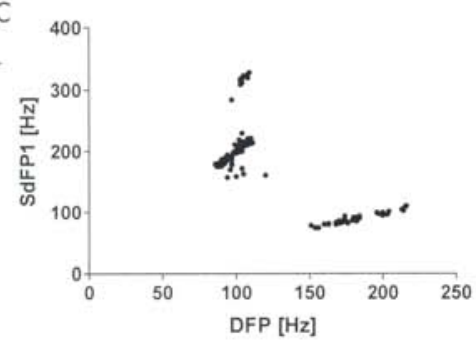

MS3
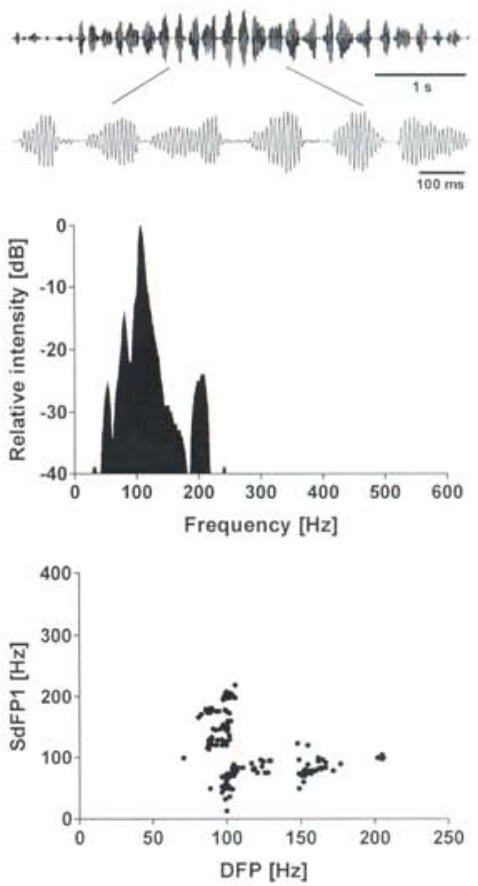

Figure 2. Oscillograms (A), frequency spectra (B) (10 s sequences) and distribution (C) of frequency values of the second (MS2, left) and the third (MS3, right) male song signal DFP and corresponding SdFP1. 
longest (12784 ms) contained 52 pulses. The frequency spectrogram of a $10 \mathrm{~s}$ MS3 pulse train showed a strong dominant frequency peak at $107 \mathrm{~Hz}$ and a peak with lower amplitude at $207 \mathrm{~Hz}$ (Figure 2B, right). Frequencies around $100 \mathrm{~Hz}$ generally dominated the MS3 pulse trains (Figure 4B), but in several examples the first part of the pulse trains contained segments with DFP around $200 \mathrm{~Hz}$ whereas in the remainder of the trains the DFP dropped to values around $100 \mathrm{~Hz}$ (Figure 4A). The relative DFP distribution of single MS3 pulses $(n=249$, $\mathrm{N}=6)$ showed peaks at $105(32.5 \%), 155(11.6 \%)$ and 205 (4\%) Hz (Figure 2C, right). Spectra of MS3 signals with about $100 \mathrm{~Hz}$ DFP values contained SdFP1 either below or above $100 \mathrm{~Hz}$ and those of signals with DFP above $150 \mathrm{~Hz}$ showed SdFP1 values only below $100 \mathrm{~Hz}$ (Figure 2C, right). MS3 pulse trains appeared to have their origins in MS1 and were emitted either in response to FS or as separate units which formed the basis for the alternating male songs during MS4 rivalry.

Male rivalry was characterized by the emission of MS4 pulses which appeared to arise from the MS2 emitted by one participant and from the MS3 emitted by the rival male (Figure 3A, left, 4B,C). MS4 pulses of mean duration varying individually between 90 and $260 \mathrm{~ms}$ were exchanged by the rival males with different repetition times that escalated into $1: 1$ alternation in fully developed rivalry. The frequency spectrogram of a typical $10 \mathrm{~s}$ long MS4 sequence showed two distinct peaks at 104 and $211 \mathrm{~Hz}$ (Figure 3B, left). The MS2 and MS3 origins of these signals are also illustrated in the sonograms (Figure 4B,C), at two frequency levels: the FM characteristics of the MS2 pulse type were exchanged with the prominent dominant frequency of about $100 \mathrm{~Hz}$ of the MS3 pulses. The relative distribution of MS4 SdFP1 according to the corresponding DFP $(n=153, N=6)$ (Figure 3C, left) mirrors the relationships characteristic for MS2 (Figure 2C, left) and MS3 (Figure 2C, right), with the spectra of pulses with DFP around $100 \mathrm{~Hz}$ containing SdFP1 above $150 \mathrm{~Hz}$, and those of above $150 \mathrm{~Hz}$ DFP containing SdFP1 of values below $100 \mathrm{~Hz}$.

\subsection{Tremulatory signals}

Tremulatory signals (Figure 3A, right, 4D,E) were produced by males and females either when touching each other or during emission of the vibratory signals. Stable repetition rates were observed only when a male tremulated in response to regularly repeated FS signals (Figure 4E). The mean duration of tremulatory signals recorded on the loudspeaker membrane ranged below
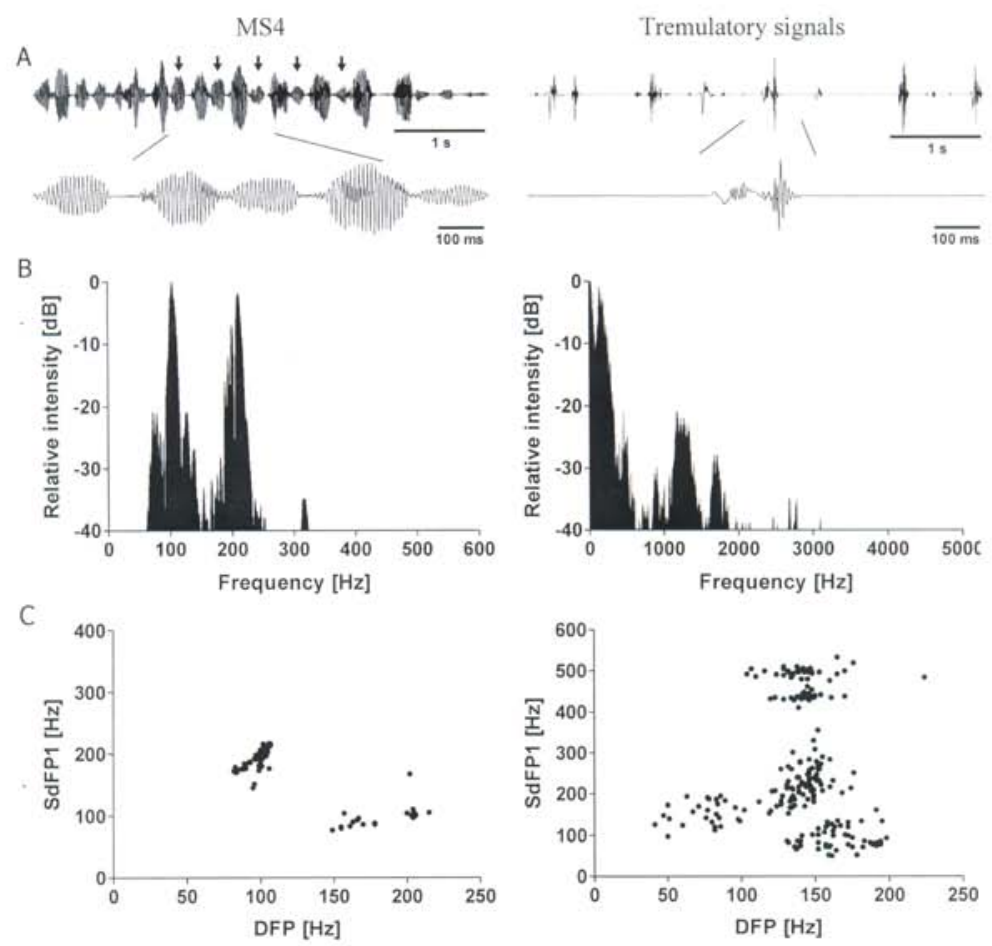

Figure 3. Oscillograms (A), frequency spectra (B) (10 s sequences) and distribution (C) of frequency values of the male fourth (MS4, left) and tremulatory signals (right) DFP and corresponding SdFP1. Different frequency scale for MS4 and tremulatory signals. Arrows (A) indicate MS4 signals emitted by the second rival male in alternation with those of the first one. 
$123 \mathrm{~ms}$ for males and females, without any observed gender specificity. The frequency spectrogram of a typical $10 \mathrm{~s}$ tremulatory signal sequence showed several peaks up to $4-5 \mathrm{kHz}$ with the dominant frequency around $131 \mathrm{~Hz}$ (Figure 3B, right, 4D). The DFP values $(\mathrm{n}=240, \mathrm{~N}=12)$ were broadly distributed between 100 and $200 \mathrm{~Hz}(16 \%$ at $150 \mathrm{~Hz})$ with $9.6 \%$ of the pulses of
DFP being below $100 \mathrm{~Hz}$ (Figure 3C, right). The SdFP1 of tremulatory signals with the $100-200 \mathrm{~Hz}$ DFP values were distributed without prominent peaks within three main frequency ranges: below 100, from 100 to 350 , and above $400 \mathrm{~Hz}$. The SdFP1 values of signals with the DFP below $100 \mathrm{~Hz}$ were distributed within the same frequency range (Figure $3 \mathrm{C}$, right).

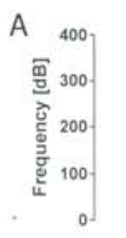
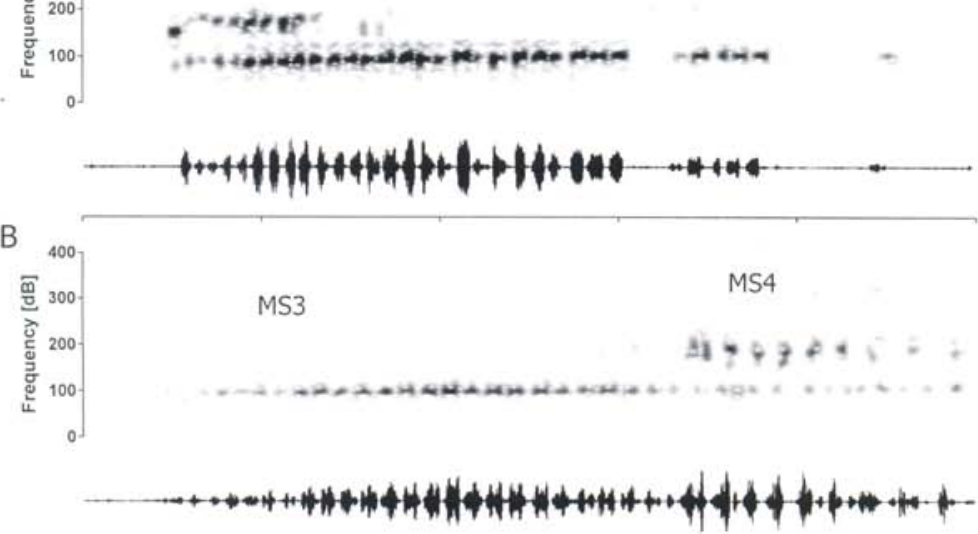

C

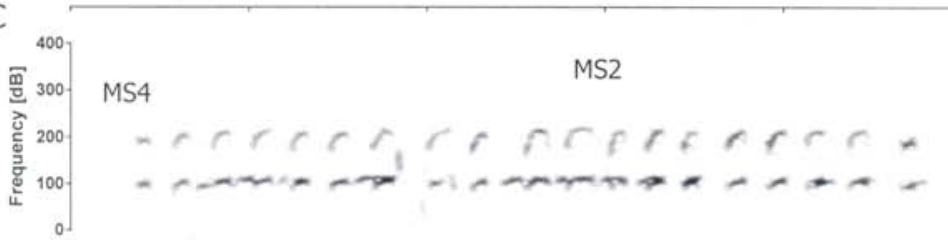

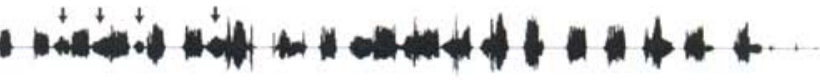

D
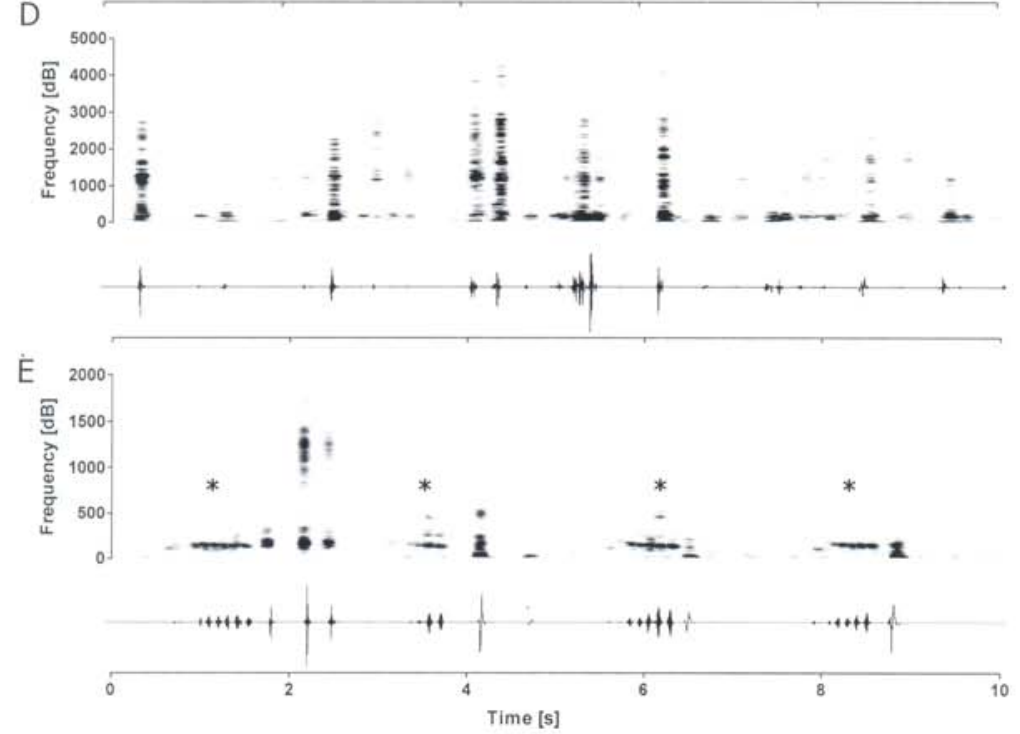

Figure 4. Sonogram (above) and oscillogram (below) of the (A) MS3 pulse train, (B) MS3 pulse train transition to MS4, (C) MS4 transition to MS2, (D) tremulatory signals and (E) tremulatory signals in alternation with FS. Time scale below the figure, different frequency axes. Arrows (C) indicate the MS4 and asterisks (E) the FS signals. 


\section{Discussion}

Vibratory and tremulatory signals produced by male and female $P$. bidens were recorded as vibrations of a nonresonant substrate to avoid any distortion of the emitted signal characteristics $[5,15,18]$ and to enable direct comparison with signals recorded from $P$. maculiventris [4] and several other stink bugs [19]. Comparison of the signals of $P$. bidens and $P$. maculiventris suggested similarities in vibration production mechanisms, but differences in the song repertoire. Both species produced signals by abdominal vibrations and tremulation, but the percussion signals recorded from $P$. maculiventris had no apparent counterpart in $P$. bidens. On the other hand, the song repertoire of P.bidens contained one female and four different male songs whereas $P$. maculiventris females were silent and males produced just one song type by abdominal vibration [4]. Tremulatory signals of both species shared similar characteristics and were comparable with signals previously reported from male $P$. bidens [14].

The $P$. bidens female song showed similar temporal characteristics to those described for other pentatomid species such as N. viridula [20] and Acrosternum impicticorne (Stål) [21]. In N. viridula, female calling triggers male searching, emission of the male calling and courtship songs, an increase in pheromone production [22], and provides directional information at plant crossings [23]. The role of the $P$. bidens female song in intraspecific communication is not clear and needs further investigation. In some respects it may substitute for an attractant pheromone [2], because the song stimulates males to respond with their own vibratory signals, as well as attracting males, and it may mediate male directional movements. It remains to be determined whether these signals may have additional functions, such as for attraction of prey, or for keeping nymphs together by means of stridulation, as shown for gregarious sawflies [24]. The female song of $P$. bidens is the first identified female vibratory signal within the subfamily Asopinae. The lack of female signals is generally more an exception than the rule: for the 18 pentatomine species for which vibrational signals have been characterized [19], only female Piezodorus lituratus (Fabricius) did not produce vibrational signals [25]. Reinvestigation of the song repertoire of the latter species may be desirable because females of the congeneric P.guildinii [21] emit calling and courtship songs.

The songs produced by male $P$. bidens are more similar to those of phytophagous stink bugs [19] than to the signals described to date from male Asopinae $[4,15]$. The MS1 short pulses triggered by signals from females give rise either to longer MS2 songs or to more complex MS3 pulse trains. The latter two songs differ in their spectral properties and in turn give rise to the MS4 rivalry songs characterized by male/male alternation with pulses with different frequency characteristics.

The production of signals by abdominal vibration at different dominant frequency levels within the same song type has not been described before from pentatomid bugs. Vibratory signals of all Pentatominae investigated to date have low-frequency narrow-band characteristics with dominant frequencies around $100 \mathrm{~Hz}$ and higher harmonics not exceeding $600 \mathrm{~Hz}$ [19]. Such frequency characteristics are well tuned to the mechanical properties of green plants [18] which transmit them efficiently over several meters, and as low-pass filters, extensively attenuate vibrations of frequencies above $400 \mathrm{~Hz}$, as shown for stridulatory signals of the burrower bug species Scaptocoris carvalhoi and S. castanea [26]. The variability of their signal spectral properties is achieved by frequency modulation, as shown for signals of $P$. lituratus [24] or Thyanta spp. [27]. Nevertheless, frequency characteristics of narrow-band, low frequency signals are modified by transmission through a plant because different ratios of spectral peak amplitudes at different distances from the source have been measured in standing wave conditions [28].

Asopinae species appear to represent the first examples among the Pentatomidae of species that enlarge the frequency communication window by using different mechanisms to produce vibrations. Tremulatory signals are more attenuated during transmission through a plant than vibratory signals of about $100 \mathrm{~Hz}$, but on the plant stem the attenuation may provide information about the distance to the source, as shown for $P$. maculiventris [5]. However, distance discrimination is less important over shorter distances and the role of tremulatory signals in predatory bugs remains an open question.

$P$. bidens produces signals of different frequencies by abdominal vibrations. This phenomenon is probably important for discrimination between the signals of different males alternating songs during rivalry singing. In the field, copulating $P$. bidens are often found in groups (O.G. Volkov, personal communication) in which production of signals of different frequencies can be an advantage in recognizing the calling or courting partner from the mixture of signals produced by the group. Such differentiation of different songs on the basis of different frequencies is a plausible hypothesis but needs confirmation. A similar effect was demonstrated in $N$. viridula females, which were found to shift the dominant frequency of their calling songs within the 70 to $130 \mathrm{~Hz}$ range to reduce interference from competitive signallers [16]. 
The results from this study leave several open questions. For example, determining the role of different body structures in signal production would clarify how vibratory signals with spectral peaks which are not simply harmonics are produced by vibration of the abdomen, and how they become dominant within the same song sequence. Further studies of substrateborne sound communication of more species could explain why female $P$. bidens produce songs, but related $P$. maculiventris do not. Such comparative studies could also determine whether the presence or absence of attractant pheromones in different asopine species correlates with broader or narrower song repertoires.

\section{Acknowledgements}

The authors are grateful to Dr. Oleg Volkov and his coworkers for hospitality in the laboratories of the Russian Plant Quarantine Centre in Bykovo, Moscow Region, Russia, where all the experiments were conducted. We thank Dr. Patrick De Clercq, University of Ghent (Belgium) and Dr. Jocelyn G. Millar (University of California Riverside (USA) for critical reading and comments on the first draft of the manuscript as well as Jernej Polajnar, National Institute of Biology Ljubljana (Slovenia) for technical assistance. The study was financially supported by the Slovenian Research Agency (Project No. J1-2133-0105).

\section{References}

[1] De Clercq P., Predaceous stinkbugs (Pentatomidae: Asopinae), In: Schaefer C.W., Panizzi A.R., (Eds.), Heteroptera of Economic Importance, CRC Press, Boca Raton, London New York Washington D.C., 2000

[2] Aldrich J.R., Chemical communication in the true bugs and parasitoid exploitation, In: Cardé R.T., Bell W.J., (Eds.), Chemical Ecology of Insects 2, Chapman \& Hall, New York, 1995

[3] Pfannenstiel R.S., Hunt R.E., Yeargan K.V., Orientation of a hemipteran predator to vibrations produced by feeding caterpillars, J. Insect Behav., 1995, 8, 1-9

[4] Žunič A., Čokl A., Virant-Doberlet M., Millar J.G., Communication with signals produced by abdominal vibration, tremulation, and percussion in Podisus maculiventris (Heteroptera: Pentatomidae), Ann. Entomol. Soc. Am., 2008, 101, 1169-1178

[5] Čokl A., Žunič A., Millar J.G., Transmission of Podisus maculiventris tremulatory signals through plants, Cent. Eur. J. Biol., 2009, 4, 585-594

[6] Larivière M.-C., Larochelle A., Picromerus bidens (Heteroptera: Pentatomidae) in North America, with a world review of its distribution in bionomics, Entomol. News, 1989, 100, 133-146

[7] Volkov O.G., Tkacheva L.B., A natural enemy of the Colorado potato beetle- Picromerus bidens, Zaschita Karantin Rustenii, 1997, 3, 30, (in Russian)

[8] Mahdian K., Kerckhove J., Tirry L., De Clercq P., Effects of diet on development and reproduction of the predatory pentatomids Picromerus bidens and Podisus maculiventris, Biocontrol, 2006, 51, 725739

[9] Mahdian K., Vantornhout I., Tirry L., De Clercq P., Effects of temperature on predation by stinkbugs

Picromerus bidens and Podisus maculiventris (Heteroptera: Pentatomidae) on noctuid caterpillars, Bull. Entomol. Res., 2006, 96, 489-496

[10] Mayné R., Breny R., Picromerus bidens L.: Morphologie. Biologie. Détermination de sa valeur d'utilisation dans la lutte biologique contre la doryphore de la pomme de terre- la valeur économique antidoryphorique des Asopines indigènes belges, Parasitica, 1948, 4, 189-224, (in French)

[11] Javahery M., Biology and ecology of Picromerus bidens (Hemiptera: Pentatomidae) in southeastern Canada, Entomol. News, 1986, 97, 87-98

[12] Aldrich J.R., Pheromones of good and bad bugs, News Bull. Entomol. Soc. Queensland, 1991, 19, 19-27

[13] McBrien H.L., Millar J.G., Phytophagous bugs, In: Hardie J., Minks A.K., (Eds.), Pheromones of nonlepidopteran insects associated with agricultural plants, CABI Publishers, Wallingford, UK, 1999

[14] Gogala M., Vibratory signals produced by Heteroptera- Pentatomorpha and Cimicomorpha, In: Drosopoulos S., Claridge M.F., (Eds), Insects Sounds and Communication: Physiology, Behaviour, Ecology and Evolution, CRC Press Taylor\&Francis Group, Boca Raton London New York, 2006

[15] Shestakov L.S., Studies of vibratory signals in pentatomid bugs (Heteroptera, Asopinae) from European Russia, Entomol. Rev., 2008, 88, 20-25

[16] Polajnar J., ČoklA., The effect of vibratory disturbance on sexual behaviour of the southern green stink bug Nezara viridula (Heteroptera, Pentatomidae), Cent. Eur. J. Biol., 2008, 2008, 3, 189-197

[17] Broughton W.B., Methods in bioacoustic terminology, In: Busnel R.G., (Ed.), Acoustic 
Behaviour of Animals, Elsevier, Amsterdam, The Netherlands, 1963

[18] Čokl A., Zorović M., Žunič A., Virant-Doberlet M., Tuning of host plants with vibratory songs of Nezara viridula L. (Heteroptera: Pentatomidae), J. Exp. Biol., 2005, 208, 1481-1488

[19] Čokl A., Stink bug interaction with host plants during communication, J. Insect Physiol., 2008, 54, 1113-1124

[20] Čokl A., Virant-Doberlet M., Stritih N. , The structure and function of songs emitted by southern green stink bugs from Brazil, Florida, Italy and Slovenia, Physiol. Entomol., 2000, 25, 196-205

[21] Blassioli-Moraes M.C., Laumann R.A., Čokl A., Borges M., Vibratory signals of four Neotropical stink bug species, Physiol. Entomol., 2005, 30, 175-188

[22] Miklas N., Lasnier T., Renou M., Male bugs modulate pheromone emission in response to vibratory signals of the conspecifics, J. Chem. Ecol., 2003, 29, 561-574

[23] Čokl A., Virant-Doberlet M., McDowell A., Vibrational directionality in the southern green stink bug Nezara viridula (L.) is mediated by female song, Anim. Behav., 1999, 58, 1277-1283
[24] Hograefe T., Substratum- stridulation in the colonial sawfly larvae of Hemichroa crocea (Geoff.) (Hymenoptera: Tenthredinidae), Zool. Anz. Jena, 1984, 213, 234-241

[25] Gogala M., Razpotnik R., Method of oscillographic sonography for bioacoustic Research, Biol. Vestnik (Ljubljana), 1974, 22, 209-216

[26] Čokl A., Nardi C., Simoes Bento J.M., Hirose E., Panizzi A.R., Transmission of stridulatory signals of the burrower bugs, Scaptocoris castanea and Scaptocoris carvalhoi (Heteroptera: Cydnidae) through the soil and soybean, Physiol Entomol., 2006, 31, 371-381

[27] McBrien H.L., Čokl A., Millar J.G., Comparison of substrate-borne signals of two congeneric stink bug species Thyanta pallidovirens and T. custator accerra (Heteroptera: Pentatomidae), J. Insect Behav., 2002, 15, 715-738

[28] Čokl A., Zorovic M., Millar J.G., Vibrational communication along plants by the stink bugs Nezara viridula and Murgantia histrionic, Behav. Proc., 2007, 75, 40-54 